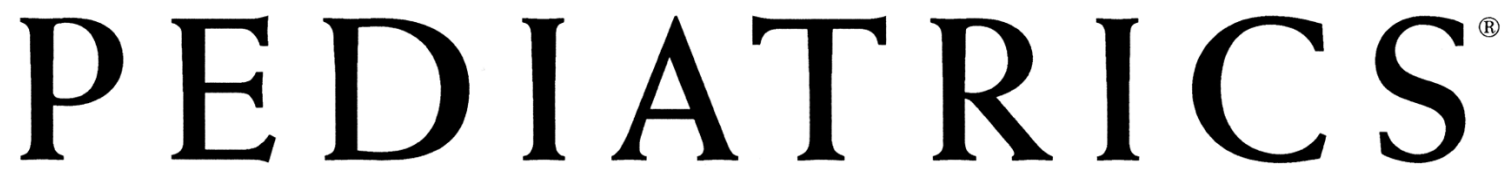

OFFICIAL JOURNAL OF THE AMERICAN ACADEMY OF PEDIATRICS

\title{
Breastfeeding and Developmental Delay: Findings From the Millennium Cohort Study
}

Amanda Sacker, Maria A. Quigley and Yvonne J. Kelly

Pediatrics 2006;118; $682-\mathrm{e} 689$

DOI: $10.1542 /$ peds.2005-3141

The online version of this article, along with updated information and services, is located on the World Wide Web at:

http://www.pediatrics.org/cgi/content/full/118/3/e682

PEDIATRICS is the official journal of the American Academy of Pediatrics. A monthly publication, it has been published continuously since 1948. PEDIATRICS is owned, published, and trademarked by the American Academy of Pediatrics, 141 Northwest Point Boulevard, Elk Grove Village, Illinois, 60007. Copyright ( 2006 by the American Academy of Pediatrics. All rights reserved. Print ISSN: 0031-4005. Online ISSN: 1098-4275.

\section{American Academy of Pediatrics}




\title{
Breastfeeding and Developmental Delay: Findings From the Millennium Cohort Study
}

\author{
Amanda Sacker, PhDa, Maria A. Quigley, MSc ${ }^{b}$, Yvonne J. Kelly, PhD \\ aDepartment of Epidemiology and Public Health, University College London, London, United Kingdom; bNational Perinatal Epidemiology Unit, University of Oxford, \\ Oxford, United Kingdom \\ The authors have indicated they have no financial relationships relevant to this article to disclose.
}

\section{ABSTRACT}

OBJECTIVE. We investigated whether the duration and exclusivity of breastfeeding affects the likelihood of gross and fine motor delay in infants and examined the effect of factors that might explain any observed differences.

METHODS. The study sample included all term singleton infants who weighed $>2500$ $\mathrm{g}$ at birth and were not placed in a special care infant unit and whose mothers participated in the first survey of the Millennium Cohort Study. Missing data reduced the sample to 14660 (94\%) with complete data.

RESULTS. Almost half $(47 \%)$ of the infants initially were exclusively breastfed, but only $3.5 \%$ of these infants were still being fed exclusively on breast milk after 4 months of age, and $34 \%$ of infants were not breastfed at all; $9 \%$ of the infants were identified with delays in gross motor coordination and $6 \%$ with fine motor coordination delays at age 9 months. The proportion of infants who mastered the developmental milestones increased with duration and exclusivity of breastfeeding. Infants who had never been breastfed were $50 \%$ more likely to have gross motor coordination delays than infants who had been breastfed exclusively for at least 4 months ( $10.7 \%$ vs $7.3 \%)$. Any breast milk also was positively related to development: infants who had never been breastfed were 30\% more likely to have gross motor delays than infants who were given some breast milk for up to 2 months $(10.7 \%$ vs $8.4 \%)$. The odds ratios for gross motor delay were not attenuated after adjustment for biological, socioeconomic, or psychosocial factors. Infants who were never breastfed had at least a $40 \%$ greater likelihood of fine motor delay than infants who were given breast milk for a prolonged period.

CONCLUSION. Our results suggest that the protective effect of breastfeeding on the attainment of gross motor milestones is attributable to some component(s) of breast milk or feature of breastfeeding and is not simply a product of advantaged social position, education, or parenting style, because control for these factors did not explain any of the observed association. In contrast, the association between breastfeeding and fine motor delay was explained by biological, socioeconomic, and psychosocial factors.

www.pediatrics.org/cgi/doi/10.1542/ peds.2005-3141

doi:10.1542/peds.2005-3141

Key Words

breastfeeding, developmental delay, Millennium Cohort

Abbreviations

MCS—Millennium Cohort Study

OR-odds ratio

Ic-PUFA_long-chain polyunsaturated

fatty acid

Accepted for publication Mar 8, 2006

Address correspondence to Yvonne J. Kelly, PhD, Department of Epidemiology and Public

Health, University College London, 1-19

Torrington PI, London WC1E 6BT. E-mail:

y.kelly@ucl.ac.uk

PEDIATRICS (IISN Numbers: Print, 0031-4005; Online, 1098-4275). Copyright $\odot 2006$ by the

American Academy of Pediatrics 
$\mathrm{T}$ HE WIDER BENEFITS of breastfeeding for health and illness prevention are widely recognized. ${ }^{1}$ The timing and the attainment of developmental milestones are important markers of neurologic integrity, and the identification of developmental delay may be important for the prevention of consequent problems, such as abnormal behaviors and long-term disability. Delay is said to occur when a child does not reach developmental milestones at expected ages, with leeway for levels of normal variation among the population. ${ }^{2}$

Observational $^{3-7}$ and experimental ${ }^{8-10}$ studies have investigated the potential role of breastfeeding on motor and cognitive development in early childhood. A recent review concluded that several studies that used different performance indicators showed positive effects of breastfeeding on developmental outcomes. ${ }^{11}$ However, the authors highlighted doubts about the strength of association, especially because most studies do not control adequately for known confounders. It is clear that both breastfeeding and certain aspects of infant development are heavily influenced by socioeconomic and psychosocial factors, ${ }^{12,13}$ and these should be taken into account in studies on infant development. Many of the experimental studies in this field have included participants from highly selected groups, such as those born preterm or with low weights, ${ }^{8-10,14}$ and it is not clear how far the results of such studies can be extrapolated to the general population.

Studies that examine dose-response relationships between breastfeeding and infant development in representative populations with control for factors that might explain observed associations are needed. We have analyzed data from the Millennium Cohort Study (MCS) of $>18500$ infants who were born in a contemporary United Kingdom setting to investigate whether the duration and the exclusivity of breastfeeding affects the likelihood of gross and fine motor delay in infants and to determine the factors that might explain any observed differences.

\section{METHODS}

The MCS sample was drawn from infants who were born in the United Kingdom during a 12-month period that spanned the years 2000-2001. The survey design, recruitment process, and fieldwork have been described in detail elsewhere. ${ }^{15}$ Briefly, it is a stratified probability sample of households that were identified through the Department of Work and Pensions Child Benefit system. Households were selected on the basis of where the family was resident just after the time of birth, and respondents in 18553 households agreed to participate in the survey, which corresponds to a response rate of $88 \%$. The sample is clustered at the electoral ward level, and economically disadvantaged wards are overrepresented (a ward is an administrative district used in local politics).

The survey involved home visits by interviewers when the cohort member was aged 9 months on average. During the interview, questions were asked about socioeconomic circumstances, household composition, adult-child interaction measures, and the health and development of the infant. In this wave of the survey, no anthropometric measures were taken.

For elimination of the effects of multiple and premature or low birth weight birth, the sample on which this analysis is based includes all term singleton infants who weighed $>2500 \mathrm{~g}$ at birth and had not been placed in a special care infant unit and whose mothers participated in the first survey of the MCS $(N=15525)$. Missing data on the breastfeeding and developmental questionnaire items reduced the sample by an additional 3 individuals to 15 522. Missing data on potential confounders reduced the sample by an additional 790, giving a sample of $14660(94 \%)$ with complete data.

\section{Breastfeeding}

Breastfeeding initiation was assessed by the question, "Did you ever try to breastfeed?" and period of continuation was computed on the basis of questions about the age of the infant when last given breast milk and when formula or other types of milk or solids first were given to the infant. From this, the breastfeeding categories were derived: (1) never breastfed, (2) short duration (ceased breastfeeding before 2 months of age), (3) intermediate duration (ceased breastfeeding at 2 months or later but before 4 months of age), (4) prolonged partial (breastfed for 4 months or more with supplementary feeds or solids started before 4 months), and (5) prolonged exclusive (breastfed for 4 months or more with supplementary feeds or solids started at 4 months or later). These categories were chosen on the basis of United Kingdom infant feeding guidelines at the time of the survey, which recommended the introduction of solids after 4 months of age, and to examine whether risk for developmental delay was contingent on the duration of breastfeeding.

\section{Developmental Delay}

The questionnaire items on developmental milestones assessed 2 areas of motor functioning: gross motor coordination and fine motor coordination. The motor functioning items are adapted from the Denver Developmental Screening test. ${ }^{16,17}$ The items that were used in the MCS were selected as those that were most appropriate for infants of 9 months. A version of the Denver Prescreening Developmental Questionnaire, a parent-answered test with a similar number of items but for a wider age range, has been used previously for community screening. ${ }^{18}$

Delay in the developmental milestones is determined when an infant has not reached a milestone that $90 \%$ of singleton MCS infants in that age group have reached. Appendix 1 gives a description of each developmental 
milestone and the proportion of MCS singletons who achieved them in each age group. The proportion of infants who had a delay on each milestone in the analysis and excluded samples also are given. For example, only $88 \%$ can move around the floor at 8 months, but $92 \%$ can do this by 9 months, so an 8 -month-old infant does not have a delay if he or she cannot move around, but an infant who is 9 months or older and cannot move around the floor is identified as having a delay on this milestone. If 1 or more gross motor or fine motor milestones is delayed, then the infant is categorized as having a delay within that specific area of development.

\section{Explanatory Factors}

We assessed the possible contributory effects of 3 sets of variables: biological, socioeconomic, and psychosocial measures. Biological variables include birth weight, gestation in weeks, mother's age in years, and smoking during pregnancy. Socioeconomic measures are the National Statistics Socio-economic Class, mother's educational qualifications, mother's employment status, and partnership status. Indicators of psychosocial well-being are mother's Malaise Inventory score (a measure of psychological distress); mother's postnatal attachment score; and the mother's attitudes toward child care, other caregivers, and the child's time spent being cared for by others.

The Malaise Inventory is a shortened version of the original 24-item scale that was developed from the Cornell Medical Index Questionnaire. ${ }^{19}$ This self-completion measure has been used widely in general population studies. ${ }^{20-22}$ In the MCS, 9 of the original 24 items of the Malaise Inventory were used. Mother's attachment to her infant is assessed by 6 Likert items that were selected from the original 19-item self-reported Condon Maternal Attachment Questionnaire. ${ }^{23}$ The attitude toward child care items were derived for the World Health Organization European Longitudinal Study of Pregnancy and Childhood. ${ }^{24}$ The 3 selected Likert items gauge what parents think about child-rearing practices that involve interactions with their infant.

Measurement of the explanatory factors is detailed in Table 1. There was no loss of fit in models that treated the Likert items as continuous variables compared with their treatment as ordinal variables. All of the psychosocial variables therefore are assumed to be measured on continuous scales. Appendix 2 gives the distribution of the explanatory factors for the analysis sample with complete data and the sample of infants who were excluded from the analysis. Given the exclusion criteria, the observed differences in the distribution of explanatory factors shown in Appendix 2 are expected.

\section{Statistical Methods}

All analyses were conducted in Stata version 8.2 with appropriate weights to adjust for oversampling in disadvantaged wards, and SEs were adjusted for the clustered sample design, so the findings represent population characteristics. Descriptive bivariate analyses are conducted to show the relationship of developmental delay to the duration and the exclusivity of breastfeeding and each of the biological, socioeconomic, and psychosocial factors. These are based on all infants who meet the selection criteria outlined above.

A series of logistic regression models investigate the relative importance of explanatory factors in accounting for breastfeeding differences in developmental delay: first, the unadjusted odds ratios (ORs) by breastfeeding type; then the ORs adjusted for biological explanatory factors, socioeconomic indicators, and psychosocial factors in turn; and finally the ORs adjusted for all explanatory factors together. The series of models is based on cases with complete data on all variables.

A more complete set of variables than those given here were viewed originally as possible explanatory factors. The final selection was chosen using the following criteria: a statistically significant $(P<.05)$ bivariate relationship with either gross motor or fine motor delay and a statistically significant independent relationship with either gross motor or fine motor delay after adjustment for other factors within the same variable set. A test of multicollinearity on all of the variables in the final fully adjusted model found evidence only of collinearity for employment status with time cared for by others.

\section{RESULTS}

Nine percent of term, singleton MCS infants who weighed $2500 \mathrm{~g}$ or more were identified with delays in gross motor coordination, and $6 \%$ were identified with fine motor coordination delays. Fewer than $1 \%$ of infants showed problems with both gross motor and fine motor coordination. Thirty-four percent of MCS mothers did not breastfeed their infant at all. Almost half $(47 \%)$ of the mothers initiated exclusive breastfeeding, but only $3.5 \%$ of infants were still being fed exclusively on breast milk after 4 months of age. The median duration of exclusive or partial breastfeeding was 4 weeks.

The proportion of infants who mastered the developmental milestones increased with duration and exclusivity of breastfeeding (Table 2). Infants who had never been breastfed were $50 \%$ more likely to have gross motor coordination delays than infants who had been breastfed exclusively for at least 4 months $(10.7 \%$ vs $7.3 \%)$. Any breast milk also was positively related to development: infants who had never been breastfed were $30 \%$ more likely to have gross motor delays than infants who were given some breast milk for up to 2 months ( $10.7 \%$ vs $8.4 \%)$. Although the point estimates for breastfeeding categories 2 to 5 were not significantly different from each other, there was a highly significant trend $(P<.0005)$ across the 5 breastfeeding categories, with no evidence of any departures from linearity. However, the linear trend was not statistically significant $(P$ 
TABLE 1 Developmental Delay in 9-Month-Old Infants of the Millennium Cohort by Biological, Socioeconomic, and Psychosocial Factors

\begin{tabular}{|c|c|c|c|}
\hline Factor & $n^{\mathrm{a}}$ & $\begin{array}{c}\text { Gross } \\
\text { Motor } \\
\text { Delay, } \%\end{array}$ & $\begin{array}{c}\text { Fine } \\
\text { Motor } \\
\text { Delay, b \% }\end{array}$ \\
\hline
\end{tabular}

Mother's age at birth, $y$

14-19

20-29

30-39

$40+$

Birth weight, $g$

2500-2999

3000-3499

3500-3999

$>4000$

Gestation, wk

37-38

$39-40$

$>40$

Smoking during pregnancy

None

$1-10 / d$

$>10 / d$

Social class

Higher professional/managerial

Lower professional/managerial

Intermediate occupations

Small employers and self employed

Lower supervisory and technical

Semiroutine occupations

Routine occupations

Unclassifiable

Mother's educational qualifications

Level 0

Level 1

Level 2

Level 3

Level 4

Level 5

Other

Mother's employment status

Full-time work

Part-time work

Nonworking

Partnership status

Partnered

Lone parent

No. of siblings

0

1

2 or more

Care while working

Parents

Relative

Nursery

Other

Not applicable

Cared for by others, h/wk

0

$1-10$

$11-20$

$21-30$

$31-40$

$41-50$

$>50$
1317

7296

6589

315

2409

6199

4858

2056

2929

8410

4183

12351

2391

780

1869

2886

1178

1535

1972

2583

2517

982

2427

1314

4478

2217

4046

535

480

2328

4388

8803

12899

2623

6371

5459

3692

1818

2656

1020

1088

8908

8104

717

2555

1908

1833

301

73

$\begin{array}{rr}6.9 & 9.7 \\ 8.7 & 6.4 \\ 9.1 & 5.2 \\ 11.7 & 4.4\end{array}$

10.6

9.6

8.0

6.7

11.5

8.6

7.4

8.6

9.2

11.9

9.1

7.7

7.0

8.3

8.3

10.0

9.5

12.7

12.8

12.2

7.5

7.5

7.7

10.9

12.5

7.4

7.6

9.9

6.5

6.9

5.4

4.6

6.9

6.2

5.0

5.8

6.8

7.2

4.8

5.0

5.7

5.8

4.8

8.0

7.1

10.4

9.8

7.1

5.3

5.4

5.1

5.2

9.7

5.2

5.2

6.7

5.7
TABLE 1 Continued

\begin{tabular}{|c|c|c|c|}
\hline Factor & $n^{\mathrm{a}}$ & $\begin{array}{c}\text { Gross } \\
\text { Motor } \\
\text { Delay, } \%\end{array}$ & $\begin{array}{c}\text { Fine } \\
\text { Motor } \\
\text { Delay, } \%\end{array}$ \\
\hline & & Mean & Mean \\
\hline Malaise scale & 14941 & & \\
\hline No delay & & 1.56 & 1.55 \\
\hline Delay & & 1.65 & 1.94 \\
\hline Postnatal attachment scale & 15030 & & \\
\hline No delay & & 51.32 & 51.35 \\
\hline Delay & & 50.92 & 50.34 \\
\hline Attitude toward stimulating infant & 14906 & & \\
\hline No delay & & 1.39 & 1.39 \\
\hline Delay & & 1.43 & 1.55 \\
\hline Attitude toward cuddling infant & 15024 & & \\
\hline No delay & & 1.17 & 1.17 \\
\hline Delay & & 1.21 & 1.25 \\
\hline Attitude toward talking to infant & 15019 & & \\
\hline No delay & & 1.18 & 1.17 \\
\hline Delay & & 1.22 & 1.27 \\
\hline
\end{tabular}

$=.21)$ when the never-breastfed infants were excluded from the analysis. The findings for fine motor functioning were similar. Again, despite no significant differences $(P=.24)$ in the point estimates for breastfeeding categories 2 to 5 , there was a significant trend $(P=.0003)$ across the 5 categories, with no evidence of any departures from linearity. Infants who were never breastfed had at least a $40 \%$ greater likelihood of fine motor delay than infants who were given breast milk for a prolonged period.

Table 1 shows the association between developmental delay and the potential explanatory variables. Differences in effects are evident. For example, whereas a greater proportion of infants who were born to older mothers had gross motor delay than infants who were born to younger mothers, the opposite was the case for fine motor delay. Mother's educational qualifications were more clearly related to fine motor than gross motor functioning. Mothers of infants with fine motor delay also had poorer Malaise Inventory scores and less positive attitudes toward childrearing than mothers of infants with gross motor delay, although they had similar scores on the postnatal attachment scale.

In Table 3, the ORs for developmental delay associated with breastfeeding are shown for the cases with complete data. There was little change in the unadjusted ORs compared with those presented in Table 2 for the full sample. The ORs for gross motor delay were unaffected by adjustment for socioeconomic or psychosocial variables and were even intensified after adjustment for the biological variables. In a model that adjusted for all of the explanatory factors simultaneously (Table 3, last column), the relationship between breastfeeding and gross motor delay remained unchanged. The linear trend just failed to reach statistical significance when the never- 
TABLE 2 Developmental Delay at 9 Months of Age According to the Duration of Breastfeeding Among 15522 Infants From the MCS

\begin{tabular}{|c|c|c|c|c|c|}
\hline \multirow[t]{2}{*}{ Breastfeeding Pattern } & \multirow[t]{2}{*}{$n^{\mathrm{a}}$} & \multicolumn{2}{|c|}{ Gross Motor Delay } & \multicolumn{2}{|c|}{ Fine Motor Delay } \\
\hline & & Proportion $^{\mathrm{b}}$ & OR $(95 \% \mathrm{Cl})$ & Proportion $^{b}$ & OR $(95 \% \mathrm{Cl})$ \\
\hline 1. Never breastfed & 5264 & 10.7 & 1.00 & 7.4 & 1.00 \\
\hline 2. Short duration & 4148 & 8.4 & $0.77(0.66-0.90)$ & 6.0 & $0.80(0.65-1.00)$ \\
\hline 3. Intermediate duration & 1389 & 7.9 & $0.71(0.56-0.91)$ & 5.3 & $0.71(0.52-0.96)$ \\
\hline 4. Prolonged partial & 2332 & 8.2 & $0.75(0.61-0.92)$ & 4.7 & $0.62(0.47-0.82)$ \\
\hline 5. Prolonged exclusive & 2389 & 7.3 & $0.66(0.54-0.79)$ & 5.4 & $0.72(0.58-0.89)$ \\
\hline Linear trend test & & & $P<.00005$ & & $P=.0003$ \\
\hline
\end{tabular}

Cl indicates confidence interval.

a Actual (unweighted) sample size.

b Weighted percentages.

TABLE 3 Odds (95\% Cls) of Developmental Delay According to Duration of Breastfeeding for 14660 Millennium Cohort Infants With No Missing Information on the Confounding Factors

\begin{tabular}{|c|c|c|c|c|c|}
\hline Breastfeeding Pattern & Unadjusted & $\begin{array}{c}\text { Adjusted for Biological } \\
\text { Factors }^{a}\end{array}$ & $\begin{array}{c}\text { Adjusted for Socioeconomic } \\
\text { Factors }{ }^{b}\end{array}$ & $\begin{array}{c}\text { Adjusted for Psychosocial } \\
\text { Factors }^{c}\end{array}$ & $\begin{array}{l}\text { Adjusted for All } \\
\text { Factors }\end{array}$ \\
\hline \multicolumn{6}{|l|}{ Gross motor delay } \\
\hline 1. Never breastfed & 1.00 & 1.00 & 1.00 & 1.00 & 1.00 \\
\hline 2. Short duration & $0.79(0.67-0.93)$ & $0.78(0.66-0.92)$ & $0.83(0.70-0.98)$ & $0.82(0.70-0.97)$ & $0.81(0.69-0.96)$ \\
\hline 3. Intermediate duration & $0.72(0.56-0.93)$ & $0.70(0.54-0.89)$ & $0.78(0.61-1.00)$ & $0.77(0.60-0.98)$ & $0.75(0.58-0.96)$ \\
\hline 4. Prolonged partial & $0.78(0.63-0.96)$ & $0.76(0.61-0.94)$ & $0.81(0.66-1.00)$ & $0.81(0.66-0.99)$ & $0.80(0.65-0.98)$ \\
\hline 5. Prolonged exclusive & $0.68(0.56-0.83)$ & $0.65(0.54-0.80)$ & $0.69(0.56-0.85)$ & $0.71(0.58-0.86)$ & $0.67(0.54-0.84)$ \\
\hline Wald test & $P=.0005$ & $P=.0001$ & $P=.005$ & $P=.005$ & $P=.002$ \\
\hline \multicolumn{6}{|l|}{ Fine motor delay } \\
\hline 1. Never breastfed & 1.00 & 1.00 & 1.00 & 1.00 & 1.00 \\
\hline 2. Short duration & $0.83(0.67-1.04)$ & $0.87(0.70-1.09)$ & $0.93(0.74-1.16)$ & $0.87(0.70-1.09)$ & $0.94(0.75-1.17)$ \\
\hline 3. Intermediate duration & $0.71(0.52-0.98)$ & $0.77(0.56-1.06)$ & $0.83(0.61-1.14)$ & $0.77(0.56-1.05)$ & $0.84(0.61-1.16)$ \\
\hline 4. Prolonged partial & $0.62(0.47-0.83)$ & $0.71(0.54-0.93)$ & $0.74(0.55-0.99)$ & $0.69(0.52-0.92)$ & $0.78(0.58-1.04)$ \\
\hline 5. Prolonged exclusive & $0.73(0.59-0.92)$ & $0.83(0.66-1.05)$ & $0.86(0.69-1.08)$ & $0.83(0.66-1.04)$ & $0.93(0.74-1.16)$ \\
\hline Wald test & $P=.005$ & $P=.11$ & $P=.30$ & $P=.09$ & $P=.49$ \\
\hline
\end{tabular}

breastfed infants were excluded $(P=.07)$. By contrast, the ORs for fine motor delay associated with breastfeeding were attenuated to nonsignificance after adjustment for the biological, socioeconomic, or psychosocial variables.

\section{DISCUSSION}

These large-scale, population-based data that were collected on infants as part of the first sweep of the MCS have provided a unique opportunity to examine the relationship between breastfeeding and attainment of developmental milestones during infancy and to investigate the factors that influence this. We have shown that infants who were never breastfed are 50\% more likely to have gross motor delay and that increasing duration of breastfeeding seems to be associated with a reduced likelihood of delay. The protective effect of breastfeeding on gross motor delay remained unexplained by a range of biological, socioeconomic, and psychosocial factors. The protective effect of breastfeeding on the likelihood of fine motor delay was explained by adjustment for biological, socioeconomic, or psychosocial factors.
These results are based on a large representative sample of infants in a contemporary setting and can be extrapolated to the general population. There was some evidence of a dose-response relationship, with the greatest protection occurring in infants who were breastfed exclusively for 4 months or more. However, some of this effect was probably attributable to "any breast milk" rather than increasing amounts, because the linear trend was only of marginal significance when the neverbreastfed infants were excluded. The data on infant feeding, although retrospective, were comprehensive and covered length of breastfeeding and timing of introduction of other milk and solids. Furthermore, recalled information on infant feeding practices has been shown to be accurate and reliable. ${ }^{25,26}$ At the time of the survey, the United Kingdom recommendations on infant feeding were for infants to be fed exclusively on breast milk for at least 4 months. Current feeding guidelines have extended this to 6 months of exclusive breastfeeding in line with World Health Organization recommendations. ${ }^{27}$ However, in the MCS, the proportion of infants who were fed exclusively on breast milk for 6 months was too low ${ }^{12}$ for this to be evaluated in relation to developmen- 
tal delay. The interview schedule asked questions on a broad range of factors relating to family circumstances, health, and development, so it is unlikely that study participants would respond to questions on feeding practices in a way that would bias the association between breastfeeding and the attainment of developmental milestones. We were able to adjust the analysis for a wide range of potential explanatory factors that we conceptually categorized as biological, socioeconomic, and psychosocial, although there are clear overlaps across these categories. A limitation of the present study was that data were collected using parental report at a single time point. Longitudinal data from the second sweep of the MCS, when children are aged 3 years, on aspects of development will be available for analysis in due course. It will be possible to examine whether protective effects of breastfeeding are sustained into early childhood.

Previous observational studies have reported positive associations between the duration of breastfeeding and motor development in infants. ${ }^{3,6,7}$ In contrast, no such association was found in 2 other studies, although these studies adjusted for a limited range of explanatory factors and may have lacked sufficient power to detect effects. $^{4,5}$ A series of experimental studies investigated the relative effects of feeding with breast and enriched formula milks on motor and cognitive development in early childhood. ${ }^{8-10,14,28,29}$ Of these studies, higher motor development scores for breastfed infants compared with their formula-fed counterparts have been reported, $, 8,28$ and the magnitude of the association was not attenuated when socioeconomic factors were taken into account. 8,9 In contrast, other experimental studies have shown no advantage for breastfed compared with formula-fed infants. ${ }^{10,29}$ Some of these studies have concentrated on the effects of particular components of breast milk. However, it is not clear which constituent(s) of breast milk might be most beneficial in promoting brain development. For example, breast milk contains long-chain polyunsaturated fatty acids (lc-PUFAs), ${ }^{30}$ which are major membrane constituents in the central nervous system and are important for normal neural function. A recent comprehensive review concluded that formula milk that was enriched with lc-PUFAs was beneficial in terms of infant motor and mental development. ${ }^{11}$ Breast milk also contains hormones, ${ }^{31}$ oligosaccharides, and other trophic factors ${ }^{32,33}$ that are important for neurodevelopment. It has been shown that levels of lc-PUFAs and oligosaccharides in breast milk are highest in the first days and weeks of lactation, ${ }^{34,35}$ and this may explain our observation that any breastfeeding has a beneficial effect on gross motor development in infancy.

\section{CONCLUSIONS}

Our results suggest that the protective effect of breastfeeding on the attainment of gross motor milestones is attributable to some component(s) of breast milk or feature of breastfeeding and is not simply a product of advantaged social position, education, or parenting style, because control for these factors did not explain any of the observed association. In contrast, the association between breastfeeding and fine motor delay was explained by biological, socioeconomic, and psychosocial factors. This is consistent with findings that show that racial/ethnic differences in infant fine motor development disappear when socioeconomic factors are taken into account. ${ }^{13}$ These results point to the need for policies that address socioeconomic circumstances and the need to encourage uptake and continuation of breastfeeding to reduce the likelihood of developmental delay and possible longer term behavioral and cognitive problems and consequent life chances.

\section{REFERENCES}

1. American Academy of Pediatrics. Policy statement: breastfeeding and the use of human milk. Pediatrics. 2005;1 15:496-506

2. First LR, Palfrey JS. The infant or young child with developmental delay. $N$ Engl J Med. 1994;330:478-483

3. Vestergaard M, Obel C, Sorensen HT, Skajaa E, Ostergaard J. Duration of breastfeeding and developmental outcomes during the latter half of infancy. Acta Paediatr. 1999;88:1327-1332

4. Paine BJ, Makrides M, Gibson RA. Duration of breast-feeding and Bayley's Mental Developmental Index at 1 year of age. $J$ Paediatr Child Health. 1999;35:82-85

5. Angelsen NK, Vik T, Jacobsen G, Bakketeig LS. Breast feeding and cognitive development at age 1 and 5 years. Arch Dis Child. 2001;85:183-188

6. Bouwstra H, Boersma ER, Boehm G, Dijck-Brouwer DA, Muskiet FA, Hadders-Algra M. Exclusive breastfeeding of healthy term infants for at least 6 weeks improves neurological condition. J Nutr. 2003;133:4243-4245

7. Agostoni C, Marangoni F, Lammardo AM, Giovannini M, Riva E, Galli C. Breastfeeding duration, milk fat composition and developmental indices at 1 year of life among breastfed infants. Prostaglandins Leukot Essent Fatty Acids. 2001;64:105-109

8. Morley R, Fewtrell MS, Abbott RA, Stephenson T, MacFadyen $\mathrm{U}$, Lucas A. Neurodevelopment in children born small for gestational age: a randomized trial of nutrient-enriched versus standard formula and comparison with a reference breastfed group. Pediatrics. 2004;113:515-521

9. Fewtrell MS, Morley R, Abbott RA, et al. Double-blind, randomized trial of long-chain polyunsaturated fatty acid supplementation in formula fed to preterm infants. Pediatrics. 2002; 110:73-82

10. O'Connor DL, Hall R, Adamkin D, et al. Growth and development in preterm infants fed long-chain polyunsaturated fatty acids: a prospective, randomized controlled trial. Pediatrics. 2001;108:359-371

11. McCann JC, Ames BN. Is docosahexaenoic acid, an n-3 longchain polyunsaturated fatty acid, required for development of normal brain function? An overview of evidence from cognitive and behavioral tests in humans and animals. Am J Clin Nutr. 2005;82:281-295

12. Kelly Y, Watt R. Breast feeding initiation and exclusive duration at 6 months by social class: results from the Millennium Cohort Study. Public Health Nutr. 2005;8:417-421

13. Kelly YJ, Sacker A, Schoon I, Nazroo J. Ethnic differences in achievement of developmental milestones by 9 months of age: the Millennium Cohort Study. Dev Med Child Neurol 2006, in press 
14. Lucas A, Fewtrell MS, Morley R, et al. Randomized trial of nutrient-enriched formula versus standard formula for postdischarge preterm infants. Pediatrics. 2001;108:703-711

15. Dex S, Joshi H, eds. Children of the 21st Century: From Birth to Nine Months. Bristol, United Kingdom: The Policy Press; 2005

16. Frankenburg WK, Dodds JB. The Denver Developmental Screening Test. J Pediatr. 1967;71:181-191

17. Frankenburg WK, Dodds JB, Archer P, Bresnick B, Shapiro H. The Denver II: Revision and Re-standardization of the DDST. Denver, CO: Developmental Materials; 1990

18. Frankenburg WK, Fandal AW, Thornton SM. Revision of Denver Prescreening Developmental Questionnaire. J Pediatr. 1987;110:653-657

19. Rutter M, Tizard J, Whitmore K. Education, Health and Behaviour. London, United Kingdom: Longmans; 1970

20. McGee R, Williams S, Silva PA. An evaluation of the Malaise Inventory. J Psychosom Res. 1986;30:147-152

21. Rutter M, Tizard J, Yule W, Graham P. Isle of Wight Studies: 1964-1974. Psychol Med. 1976;6:313-332

22. Rodgers B, Pickles A, Power C, Collishaw S, Maughan B. Validity of the Malaise Inventory in general population samples. Soc Psychiatry Psychiatr Epidemiol. 1999;34:333-341

23. Condon JT, Corkindale CJ. The assessment of parent-to-infant attachment: development of a self-report questionnaire instrument. J Reprod Infant Psychol. 1998;16:57-76

24. Kukla L, Bouchalová M, Stejskal J. Manual of National Study of ELSPAC Project. Brno, Czech Republic: Research Paedagogic Institute (RIP); 1990

25. Eaton-Evans J, Dugdale AE. Recall by mothers of the birth weights and feeding of their children. Hum Nutr Appl Nutr. 1986;40:171-175
26. Li R, Scanlon KS, Serdula MK. The validity and reliability of maternal recall of breastfeeding practice. Nutr Rev. 2005;63: 103-110

27. World Health Organization. Global Strategy for Infant and Young Child Feeding. Geneva, Switzerland: World Health Organization; 2002

28. Lucas A, Morley R, Cole TJ, Gore SM. A randomized multicentre study of human milk versus formula and later development in preterm infants. Arch Dis Child Fetal Neonatal Ed. 1994; 70:F141-F146

29. Lucas A, Stafford M, Morley R, et al. Efficacy and safety of long-chain polyunsaturated fatty acid supplementation of infant-formula milk: a randomised trial. Lancet. 1999;354: $1948-1954$

30. Innis SM. Human milk and formula fatty acids. J Pediatr. 1992; 120:S56-S61

31. Sack J. Hormones in milk. In: Freier S, Eidelman AI, eds. Human Milk: Its Biological and Social Value. Amsterdam, Netherlands: Excerpta Medica; 1980:56-61

32. Donovan SM, Odle J. Growth factors in milk as mediators of infant development. Annu Rev Nutr. 1994;14:147-167

33. Uauy R, De Andraca I. Human milk and breastfeeding for optimal human development. J Nutr. 1995;125: 2278S-2280S

34. Guesnet P, Antoine JM, Rochette de Lempdes JB, Galent A, Durand G. Polyunsaturated fatty acid composition of human milk in France: changes during the course of lactation and regional differences. Eur J Clin Nutr. 1993;47:700-710

35. Coppa GV, Gabrielli O, Pierani P, Catassi C, Carlucci A, Giorgi PL. Changes in carbohydrate composition in human milk over 4 months of lactation. Pediatrics. 1993;91:637-641

\begin{tabular}{|c|c|c|c|c|c|c|c|c|}
\hline \multirow[t]{3}{*}{ APPENDIX 1} & \multicolumn{8}{|c|}{$\begin{array}{l}\text { Percentage of MCS Singleton Infants Who Achieved Developmental Milestones by Age in Months and the Proportion of Infants } \\
\text { With Developmental Delay }\end{array}$} \\
\hline & & \multicolumn{5}{|c|}{ Singleton Infants Who Achieved Development Milestone, \% } & \multicolumn{2}{|c|}{ Infants Who Had a Delay, \% } \\
\hline & & $n$ & $8 \mathrm{mo}$ & $9 \mathrm{mo}$ & $10 \mathrm{mo}$ & $\geq 11 \mathrm{mo}$ & $\begin{array}{l}\text { Analysis } \\
\text { Sample }^{a}\end{array}$ & $\begin{array}{l}\text { Excluded } \\
\text { Sample }^{b}\end{array}$ \\
\hline \multicolumn{9}{|c|}{ Gross motor coordination } \\
\hline Infant can sit & p without being supported & 18276 & 92.40 & 95.79 & 97.91 & 98.68 & 2.62 & 11.90 \\
\hline $\begin{array}{l}\text { If infant is pu } \\
\text { can move } \\
\text { another }\end{array}$ & $\begin{array}{l}\text { down on the floor, he or she } \\
\text { bout from one place to }\end{array}$ & 18276 & 87.78 & 92.28 & 93.89 & 96.66 & 6.42 & 11.73 \\
\hline $\begin{array}{l}\text { Infant can st } \\
\text { somethin }\end{array}$ & $\begin{array}{l}\text { d up while holding onto } \\
\text { such as furniture }\end{array}$ & 18276 & 54.81 & 68.68 & 79.01 & 90.51 & 0.17 & 0.35 \\
\hline Infant can w & k a few steps on his or her own & 18276 & 1.11 & 4.00 & 9.24 & 21.09 & 0.00 & 0.00 \\
\hline \multicolumn{9}{|c|}{ Fine motor coordination } \\
\hline Infant grabs & bjects using the whole hand & 18277 & 99.34 & 99.38 & 99.36 & 99.51 & 0.52 & 1.60 \\
\hline $\begin{array}{l}\text { Infant passes } \\
\text { hand to a }\end{array}$ & $\begin{array}{l}\text { toy back and forth from one } \\
\text { ther }\end{array}$ & 18259 & 93.25 & 95.12 & 95.57 & 97.79 & 4.40 & 6.68 \\
\hline $\begin{array}{l}\text { Infant can pi } \\
\text { forefinger }\end{array}$ & $\begin{array}{l}\text { up a small object using } \\
\text { nd thumb only }\end{array}$ & 18228 & 83.30 & 88.84 & 92.29 & 94.18 & 1.33 & 2.95 \\
\hline Infant puts $h$ & or her hands together & 18266 & 75.99 & 83.56 & 89.26 & 94.03 & 0.10 & 0.23 \\
\hline
\end{tabular}

Numbers are the raw values, and percentages are adjusted for the clustered survey design and weighted to the UK population.

a Term singleton infants who weighed $>2500 \mathrm{~g}$ and were not placed in special infant unit and whose mothers were the main respondent.

b One or more of preterm, low birth weigh, multiple birth, in special infant unit, and respondent not natural mother. 


\begin{tabular}{|c|c|c|c|c|c|c|c|c|c|}
\hline \multirow[t]{4}{*}{ APPENDIX 2} & \multirow{2}{*}{\multicolumn{4}{|c|}{$\begin{array}{l}\text { Distribution of Biological, Socioeconomic, and } \\
\text { Psychosocial Factors for the Analysis Sample and } \\
\text { Excluded Sample of Infants in the MCS }\end{array}$}} & \multirow{2}{*}{\multicolumn{2}{|c|}{ APPENDIX 2 Continued }} & \multirow[b]{2}{*}{$\begin{array}{c}\text { Analysis } \\
\text { Sample, } \%\end{array}$} & \multirow[b]{2}{*}{$\begin{array}{c}\text { Excluded } \\
\text { Sample, }^{\text {a } \%}\end{array}$} & \multirow[b]{2}{*}{$p \mathrm{~b}$} \\
\hline & & & & & & & & & \\
\hline & & Analysis & Excluded & $p^{b}$ & $41-50$ & & 2.18 & 1.99 & \\
\hline & & Sample, ${ }^{\text {a }} \%$ & Sample, a \% & & $>50$ & & 0.59 & 0.53 & \\
\hline \multicolumn{2}{|c|}{ Mother's age at birth, $y$} & & & .02 & & & Mean & Mean & \\
\hline \multicolumn{2}{|c|}{$14-19$} & 7.07 & 7.88 & & Malaise scale & 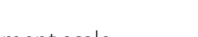 & 1.56 & 1.82 & $<.00005$ \\
\hline \multicolumn{2}{|l|}{$20-29$} & 43.46 & 43.51 & & Postnatal attach & iment scale & 51.30 & 50.94 & .002 \\
\hline \multicolumn{2}{|l|}{$30-39$} & 47.39 & 45.65 & & Attitude toward & stimulating infant & 1.40 & 1.41 & .26 \\
\hline \multicolumn{2}{|l|}{$40+$} & 2.09 & 2.96 & & Attitude toward & cuddling infant & 1.17 & 1.19 & .02 \\
\hline \multicolumn{2}{|l|}{ Birth weight, g } & & & $<.00005$ & Attitude toward & talking to infant & 1.18 & 1.20 & .007 \\
\hline$<2500$ & & 0.00 & 37.79 & & & means are adjusted fo & ne clustered surv & & ed to the UK \\
\hline $2500-2999$ & & 14.16 & 21.19 & & population. & 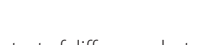 & $\sqrt{2}+5$ & 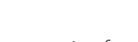 & 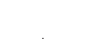 \\
\hline $3000-3499$ & & 39.35 & 21.27 & & b Pearson $\chi^{2}$ test o & r test of difference betv & en means, both $y$ & correction for $\mathrm{c}$ & tered survey \\
\hline 3500-3999 & & 32.60 & 13.31 & & & & & & \\
\hline$>4000$ & & 13.89 & 6.43 & & & & & & \\
\hline Gestation, wk & & & & $<.00005$ & & & & & \\
\hline$<37$ & & 0.00 & 40.94 & & & & & & \\
\hline $37-38$ & & 19.05 & 21.29 & & & & & & \\
\hline $39-40$ & & 53.46 & 27.27 & & & & & & \\
\hline$>40$ & & 27.49 & 10.49 & & & & & & \\
\hline Smoking during & pregnancy & & & $<.00005$ & & & & & \\
\hline 0 & & 81.70 & 78.23 & & & & & & \\
\hline $1-10 / d$ & & 13.91 & 15.71 & & & & & & \\
\hline$>10 / d$ & & 4.39 & 6.06 & & & & & & \\
\hline Social class & & & & $<.00005$ & & & & & \\
\hline Higher profes & sional/managerial & 16.05 & 14.13 & & & & & & \\
\hline Lower profes & ional/managerial & 22.08 & 18.45 & & & & & & \\
\hline Intermediate & occupations & 7.63 & 6.14 & & & & & & \\
\hline Small employ & ers and self employed & 1.06 & 9.96 & & & & & & \\
\hline Lower superv & sory and technical & 12.61 & 12.78 & & & & & & \\
\hline Semiroutine & ccupations & 13.73 & 15.74 & & & & & & \\
\hline Routine occu & Dations & 13.45 & 15.88 & & & & & & \\
\hline Unclassifiable & & 3.85 & 6.94 & & & & & & \\
\hline Mother's educat & ional qualifications & & & $<.00005$ & & & & & \\
\hline Level 0 & & 10.37 & 19.16 & & & & & & \\
\hline Level 1 & & 8.14 & 8.11 & & & & & & \\
\hline Level 2 & & 29.97 & 18.18 & & & & & & \\
\hline Level 3 & & 14.53 & 12.97 & & & & & & \\
\hline Level 4 & & 30.84 & 25.75 & & & & & & \\
\hline Level 5 & & 4.02 & 2.62 & & & & & & \\
\hline Other & & 2.13 & 3.22 & & & & & & \\
\hline Mother's emplo) & ment status & & & $<.00005$ & & & & & \\
\hline Full-time wor & & 15.19 & 13.51 & & & & & & \\
\hline Part-time wor & & 32.29 & 25.83 & & & & & & \\
\hline Nonworking & & 52.52 & 60.66 & & & & & & \\
\hline Partnership statu & & & & .001 & & & & & \\
\hline Partnered & & 86.68 & 84.36 & & & & & & \\
\hline Lone parent & & 13.32 & 15.64 & & & & & & \\
\hline No. of siblings & & & & $<.00005$ & & & & & \\
\hline 0 & & 41.78 & 40.49 & & & & & & \\
\hline 1 & & 37.13 & 33.59 & & & & & & \\
\hline 2 or more & & 21.10 & 25.92 & & & & & & \\
\hline Care while work & & & & $<.00005$ & & & & & \\
\hline Parents & & 13.35 & 10.65 & & & & & & \\
\hline Relative & & 17.10 & 12.74 & & & & & & \\
\hline Nursery & & 8.28 & 5.21 & & & & & & \\
\hline Other & & 8.14 & 6.42 & & & & & & \\
\hline Not applicabl & & 53.14 & 64.98 & & & & & & \\
\hline Cared for by oth & ers, h/wk & & & $<.00005$ & & & & & \\
\hline 0 & & 47.54 & 55.40 & & & & & & \\
\hline $1-10$ & & 5.94 & 4.28 & & & & & & \\
\hline $11-20$ & & 18.48 & 14.70 & & & & & & \\
\hline $21-30$ & & 13.74 & 11.08 & & & & & & \\
\hline $31-40$ & & 11.54 & 12.01 & & & & & & \\
\hline
\end{tabular}




Breastfeeding and Developmental Delay: Findings From the Millennium Cohort
Study
Amanda Sacker, Maria A. Quigley and Yvonne J. Kelly
Pediatrics 2006;118;e682-e689
DOI: $10.1542 / p e d s .2005-3141$

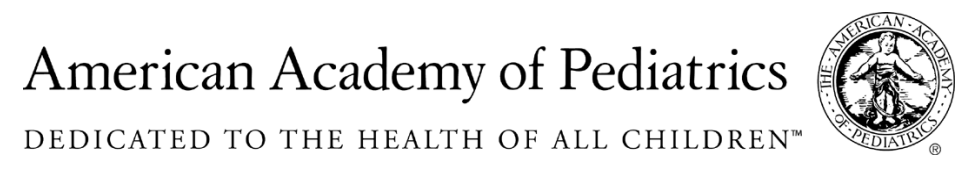

